\title{
Serological prevalence of six vector-borne pathogens in dogs presented for elective ovariohysterectomy or castration in the South central region of Texas
}

\author{
J. Mack Fudge ${ }^{1}$, Bailey Boyanowski', Bernie Page ${ }^{1}$, Shuling Liu² and Artem S. Rogovskyy ${ }^{3^{*}}$ (D)
}

\begin{abstract}
Background: Most vector-borne pathogens cause zoonotic diseases. These zoonoses often have wild animal reservoirs that play a significant role in disease epidemiology. However, pet animals have also been implicated in transmission of zoonotic agents to humans. To exemplify, dogs are competent reservoir hosts for several zoonotic vector-borne bacteria and protozoa. Despite that vector-borne diseases can be life-threatening for both pets and humans, studies on pathogen seroprevalence are very limited. Therefore, the objective of this study was to determine the serological prevalence of six zoonotic vector-borne agents in dogs from the South Central region of Texas (US).

Electronic medical records of dogs, presenting over 2014-2019 for elective ovariohysterectomy or castration at a high volume spay and neuter clinic, were reviewed for serological testing. Sera from 418 dogs were tested for the Dirofilaria immitis antigen, and antibodies to Anaplasma phagocytophilum, Anaplasma platys, Borrelia burgdorferi, Ehrlichia canis, and Ehrlichia ewingi, using a commonly available commercial test kit. Descriptive statistics were computed to characterize the respective seroprevalence rates of the dog population. The study involved 192 (46\%) male and 226 (54\%) female dogs.
\end{abstract}

Results: Overall, 85 (20\%) dogs tested positive for at least one of the 6 pathogens investigated. The highest seroprevalence rate averaged over the 6-year period was $11.7 \%$ for D. immitis followed by $8.4 \%$ for $E$. canis and/or $E$. ewingii, 4.3\% for A. phagocytophilum and/or A. platys, and 0.2\% for B. burgdorferi. The co-exposure or co-infection was only detected in $3.8 \%$ of the dog population.

Conclusions: Together, opportunistic testing of dogs presenting for elective surgical procedures may provide an effective way of assessing seroprevalence and/or risk factors for common vector-borne diseases within a geographic region of concern.

Keywords: Anaplasmosis, Ehrlichiosis, Heartworm, Lyme borreliosis, Seroprevalence, Tick-borne pathogens

\footnotetext{
* Correspondence: arogovskyy@tamu.edu

${ }^{3}$ Department of Veterinary Pathobiology, College of Veterinary Medicine and Biomedical Sciences, Texas A\&M University, College Station, TX 77843, USA

Full list of author information is available at the end of the article
}

(c) The Author(s). 2020 Open Access This article is licensed under a Creative Commons Attribution 4.0 International License, which permits use, sharing, adaptation, distribution and reproduction in any medium or format, as long as you give appropriate credit to the original author(s) and the source, provide a link to the Creative Commons licence, and indicate if changes were made. The images or other third party material in this article are included in the article's Creative Commons licence, unless indicated otherwise in a credit line to the material. If material is not included in the article's Creative Commons licence and your intended use is not permitted by statutory regulation or exceeds the permitted use, you will need to obtain permission directly from the copyright holder. To view a copy of this licence, visit http://creativecommons.org/licenses/by/4.0/. The Creative Commons Public Domain Dedication waiver (http://creativecommons.org/publicdomain/zero/1.0/) applies to the data made available in this article, unless otherwise stated in a credit line to the data. 


\section{Background}

Vectors are commonly defined as blood-feeding arthropods (e.g., mosquitoes, ticks) that transmit pathogens between hosts $[1,2]$. Unfortunately, diseases caused by the vector-borne pathogens are widespread world-wide. Reported human cases of vector-borne diseases in the United States (US) alone have more than tripled since 2004 and are overall characterized by steadily increasing incidence of tick-borne diseases and sporadic outbreaks of mosquito-borne diseases [3]. In the US, well over 600, 000 human cases of vector-borne diseases were recorded during 2004-2016, with tick-borne diseases accounting for nearly three-quarters of those cases. In the same period, human cases of tick-borne diseases doubled. Lyme borreliosis accounted for $82 \%$ of all reported tickborne diseases, and the incidence of anaplasmosis and ehrlichiosis increased yearly [4].

Vector-borne disease epidemiology is complex because of environmental influence on vectors [5]. The dynamics of vector-borne pathogen transmission are determined by the interactions between pathogen, vector, reservoir, host, and environmental factors [4, 5]. Furthermore, some arthropods are competent vectors for transmission of more than one pathogen [6]. Most vector-borne pathogens are zoonotic. Arthropod vectors can bridge the gap between animals and humans that do not ordinarily interact [4]. Vector-borne zoonoses, often having wild animal reservoirs, can be difficult or impossible to eradicate [4].

Tick-borne pathogens rarely cause sudden epidemics in people for several reasons. Tick mobility is limited to the movement of its animal hosts [7]. Humans are mostly incidental hosts. Additionally, the prolonged life cycle and widely separated blood meals of ticks limit their ability for rapid or wide-spread transmission of disease pathogens [4].

In addition to wildlife reservoir, pet animals have also been implicated in the transmission of zoonotic agents to humans. Pets may come in close contact with wild animals or vectors that have previously been exposed to reservoir animals [5]. As an example, dogs are competent reservoir hosts for several zoonotic vector-borne bacteria and protozoa and can be an important source of nutrition for many blood-sucking arthropods like fleas, mosquitoes, sand flies, and ticks [6, 8, 9]. This suggests that household pets may offer a relatively accessible sentinel for vector-borne zoonotic diseases.

Canine vector-borne diseases (CVBDs) are caused by widely distributed and various arthropod-borne pathogens [10]. Anaplasmosis and ehrlichiosis are emerging bacterial diseases that affect dogs and humans in North America and other parts of the world [11, 12]. Anaplasma phagocytophilum (A. phagocytophilum) is a causative agent of granulocytotropic anaplasmosis and is transmitted by
Ixodes species ticks (e.g., the blacklegged tick, Ixodes scapularis (I. scapularis)) [13-15]. Anaplasma platys (A. platys), which is putatively transmitted by the brown dog tick, Rhipicephalus sanguineus ( $R$. sanguineus), causes canine infectious thrombocytopenia and was recently implicated in human disease cases [16-20]. Ehrlichia canis (E. canis) and Ehrlichia ewingii (E. ewingii), the agents of ehrlichiosis, are transmitted by $R$. sanguineus and the lone star tick, Amblyoma americanum (A. americanum), respectively [21, 22]. Importantly, dogs are considered natural hosts for A. platys, E. canis, and potentially E. ewingii $[23,24]$ and can remain infected for many months or years. In 2014, an infection with A. platys, E. ewingii, and Ehrlichia chaffeenis (E. chaffeenis) was described in a dog and two family members providing molecular evidence of persistent infection in humans [18]. Subsequently, a human chronic infection with $E$. chaffeensis was reported in 2015 [25]. The bacterial infections may develop into chronic debilitating diseases [21, 23, 26]. Dogs can also become persistently infected with Borrelia burgdorferi ( $B$. burgdorferi) via exposure to Ixodes species ticks. In North America, human Lyme disease and canine borreliosis is caused by $B$. burgdorferi sensu stricto, which is transmitted by I. scapularis and Ixodes pacificus [27]. Finally, heartworm is one of the most important helminthic diseases of canids in North America and its causative agent is the mosquito-transmitted nematode, Dirofilaria immitis (D. immitis) (Leidy 1856) [28-30] D. immitis is responsible for canine cardiopulmonary dirofilariasis and human pulmonary dirofilariasis [31]. This zoonotic parasite is mainly located in temperate, tropical, and subtropical areas of the world [31-34]. Human cases have been reported mainly in areas of high canine prevalence, highlighting the importance of heartworm testing and chemoprophylaxis in dogs to reduce transmission [35].

Despite that the above described agents of CVBDs can be life-threatening for pets and directly affect human health, studies on the seroprevalence of vector-borne pathogens in animals are quite limited [5]. Therefore, the objective of this study was to determine the serological prevalence of six vector-borne pathogens in dogs (A. phagocytophilum, A. platys, B. burgdorferi, E. canis, E. ewingii, and $D$. immitis) presented for elective surgery at a high volume spay and neuter practice in the South Central region of Texas (US).

\section{Results}

\section{Study animals}

During the study period, 418 presumed healthy dogs were identified as serologically tested for the presence of antibodies to bacterial pathogens of anaplasmosis (A. phagocytophilum and A. platys), ehrlichiosis (E. canis and E. ewingii), and borreliosis (B. burgdorferi); and the antigen of heartworm (D. immitis). The study 
dogs included 192 (46\%) males and 226 (54\%) females. Their reported ages varied from 6 months to 18 years with the median age being 4 years. The data represented a total of 60 general breed types reported by owner/agents: Terrier mix $(n=51)$, Chihuahua $(n=50)$, Labrador Retriever $(n=41)$, Pit Bull $(n=25)$, Dachshund $(n=22)$, Shepherd mix $(n=17)$, Boxer $(n=13)$, Shih Tzu $(n=13)$, Chihuahua/Dachshund mix $(n=11)$, Great Pyrenees $(n=11)$, Australian Cattle Dog $(n=8)$, German Shepherd $(n=8)$, Poodle $(n=$ 7), Schnauzer $(\mathrm{n}=7)$, Beagle $(n=6)$, Border Collie $(n=6)$, Great Dane $(n=6)$, Husky $(n=6)$, Mastiff $(n=$ 6), Miniature Pinscher $(n=6)$, Yorkshire Terrier $(n=$ 6), Australian Shepherd $(n=5)$, Maltese $(n=5)$, Wirehaired Terrier $(n=5)$, Doberman Pinscher $(n=4)$, Heeler $(n=4)$, Hound $(n=4)$, Jack Russel Terrier $(n=$ 4), Belgian Malinois $(n=3)$, Bull Dog $(n=3)$, Cairn Terrier $(n=3)$, Catahoula Leopard Dog $(n=3)$, Golden Retriever $(n=3)$, Papillon $(n=3)$, Retriever mix $(n=3)$, Shar Pei $(n=3)$, Spaniel $(n=3)$, Welsh Corgi $(n=3)$, Bassett Hound $(n=2)$, Black Mouth Cur $(n=2)$, Chow Chow $(n=2)$, Coonhound $(n=2)$, Lhasa Apso $(n=2)$, Pekingese $(n=2)$, Pointer $(n=2)$, Pomeranian $(n=2)$, Rottweiler $(n=2)$, American Eskimo $\operatorname{Dog}(n=1)$, Basenji $(n=1)$, Bichon Frise $(n=1)$, Blue Lacy $(n=1)$, Boston Terrier $(n=1)$, Brussels Griffon $(n=1)$, Chinese Crested $(n=1)$, Cocker Spaniel $(n=$ $1)$, Manchester Terrier $(n=1)$, Pug $(n=1)$, Rhodesian Ridgeback $(n=1)$, Weimaraner $(n=1)$, and West Highland Terrier $(n=1)$. Based upon the information provided by the owners or agents, $62(14.8 \%)$ dogs were privately-owned and the other 356 (85.2\%) dogs were rescued or under the possession of community animal control facilities. Of the privately-owned animals with pre-existing medical records, 21 (33.9\%) were being administered flea and/or heartworm prophylaxis at the time of blood collection.

\section{Serology}

A summary of SNAP 4Dx Plus (IDEXX Laboratories Inc., Westbrook, ME, US) (SNAP) test results is provided in Table 1 . The combined data showed that $20.3 \%$ of the dogs ( 85 out of 418) were exposed to or infected with at least one of the 6 pathogens. There were no significant differences associated with sex or age between the dogs with positive and negative test results. However, the dogs that tested positive for any of the 6 pathogens (the median body weight of $19.0 \mathrm{kgs}$, range 2.5 to $56.0 \mathrm{kgs})$ were significantly heavier than the serologically negative dogs (median $10.9 \mathrm{kgs}$, range 1.4 to $55.5 \mathrm{kgs}$; $P=0.01$ ).

The results showed that $4.3 \%$ of the dogs (11 females and 7 males) tested positive for antibodies to $A$. phagocytophilum and/or $A$. platys (Table 1 ). The median age was 4 years (range 10 months to 8 years) and 3 dogs were reported under 2 years of age. The median weight was $14.4 \mathrm{kgs}$ (range 2.5 to $34.1 \mathrm{kgs}$ ). No significant differences associated with age or weight of the Anaplasmapositive dogs were identified when compared to the dogs that tested negative by the SNAP test.

There were $8.4 \%$ of the dogs ( 15 females and 20 males) that tested positive for anti-Ehrlichia antibodies (Table 1). The median age and weight were 4.5 years (range 10 months to 10 years) and $15.1 \mathrm{kgs}$ (range 2.5 to $33 \mathrm{kgs}$ ), respectively. Four dogs were reported to be under 2 years of age. There were no significant differences in age or weight between the Ehrlichia-positive and serologically negative dogs. Two of the 35 dogs were retested a month later, and their blood samples remained positive (data not shown).

Of the $11.7 \%$ of the dogs ( 25 females and 24 males) that tested positive for canine heartworm, the median age of 5 years (range 6 months to 11 years) was significantly higher than the respective ages of the dogs that tested negative for any of the other 5 pathogens $(P<$

Table 1 Summary of vector-borne disease serological test results for canine patients admitted to a high volume spay and neuter practice in the South Central region of Texas over 2014-2019

\begin{tabular}{llllllll}
\hline Categories & \multicolumn{2}{l}{ Number (\%) of positive dogs via SNAP tests by year } & \multicolumn{2}{l}{ Total } \\
\cline { 2 - 6 } Year & $\mathbf{2 0 1 4}$ & $\mathbf{2 0 1 5}$ & $\mathbf{2 0 1 6}$ & $\mathbf{2 0 1 7}$ & $\mathbf{2 0 1 8}$ & $\mathbf{2 0 1 9}$ \\
\hline An ab $^{\mathrm{a}}$ & $2(3.7)$ & $0(0)$ & $0(0)$ & $6(6.5)$ & $5(4.9)$ & $5(3.8)$ & $18(4.3)$ \\
$\mathrm{Bb} \mathrm{ab}^{\mathrm{a}}$ & $0(0)$ & $0(0)$ & $1(4.5)$ & $0(0)$ & $0(0)$ & $0(0)$ & $1(0.2)$ \\
Eh ab $^{\mathrm{a}}$ & $7(13.0)$ & $0(0)$ & $2(9.1)$ & $11(11.8)$ & $6(5.8)$ & $9(6.8)$ & $35(8.4)$ \\
Di ag $^{\mathrm{a}}$ & $5(9.3)$ & $3(21.4)$ & $3(13.6)$ & $8(8.6)$ & $12(11.7)$ & $18(13.6)$ & $49(11.7)$ \\
Total test-positive dogs $^{\mathrm{b}}$ & $11(20.4)$ & $3(21.4)$ & $4(18.2)$ & $20(21.5)$ & $19(18.4)$ & $28(21.2)$ & $85(20.3)$ \\
Total test-negative dogs $^{c}$ & $43(79.6)$ & $11(78.6)$ & $18(81.8)$ & $73(78.5)$ & $84(81.6)$ & $104(78.8)$ & $333(79.7)$ \\
Total dogs tested & 54 & 14 & 22 & 93 & 103 & 132 & 418 \\
\hline
\end{tabular}

${ }^{\mathrm{a}}$ An ab, anti-Anaplasma phagocytophilum and/or Anaplasma platys antibodies; Bb ab, anti-Borrelia burgdorferi antibodies; Eh ab, anti-Ehrlichia canis and/or Ehrlichia ewingii antibodies; Di ag, Dirofilaria immitis antigen

${ }^{b}$ Number of positive dogs by any of the four SNAP test results

${ }^{\mathrm{C}}$ Number of negative dogs by all four SNAP test results 
$0.01)$. Only 2 dogs were reported to be under 2 years of age. The median weight for the heartworm antigenpositive dogs was $20.2 \mathrm{kgs}$ (range 2.7 to $56.0 \mathrm{kgs}$ ), which was heavier than the dogs that were negative for any of the other pathogens tested $(P<0.05)$.

In contrast to the above test results, only one male dog out of $418(0.2 \%)$ tested positive for antibodies to $B$. burgdorferi (Table 1). Exposure to or infection with 2 or more pathogens (referred to here as co-infection) was detected in $3.8 \%$ out of 418 dogs (7 females and 9 males). Specifically, 8 dogs were serologically positive for Anaplasma and Ehrlichia, and 4 dogs tested positive for Ehrlichia and heartworm. One dog tested positive for Anaplasma and heartworm, and another dog was seropositive for B. burgdorferi and Ehrlichia. Lastly, two dogs tested positive for Anaplasma, Ehrlichia, and heartworm. The median age for the co-infected animals was 4 years (range 2 to 6 years). The dogs' median weight was $9 \mathrm{kgs}$ (range 2.5 to $32 \mathrm{kgs}$ ).

\section{Estimated true prevalence}

Based on the sensitivity and specificity of the SNAP test, the estimated true prevalence $(95 \% \mathrm{CI})$ was calculated for Ehrlichia, 3.98\% (1.50 to 7.28\% (Lower, Upper 95\% CI)) and D. immitis, $11.21 \%$ (8.42 to $14.71 \%$ ). Given the low number of dogs that tested positive for Anaplasma $(n=18)$ or B. burgdorferi $(n=1)$, it was not possible to accurately assess the true prevalence for these two pathogens.

\section{Discussion}

Dogs are considered not only biological hosts for most canine vector-borne diseases, but also important environmental sentinels for determining the frequency and distribution of infected vector populations [36-39]. Moreover, recently, dogs facilitated the efforts to better understand the potential public health implications of various canine vector-borne disease pathogens [6]. Given their sentinel role and the scarcity of seroprevalence data in dog populations, the objective of this study was to use a convenience sample of dogs presenting for elective surgical neutering at a high volume surgical practice to identify the serological prevalence of $A$. phagocytophilum, A. platys, B. burgdorferi, E. canis, E. ewingii, and D. immitis in dogs from the Greater San Antonio area. Based upon the information provided by the owners or agents, $62(14.8 \%)$ dogs in this study were privatelyowned and the other $356(85.2 \%)$ dogs were rescued or under the possession of community animal control facilities. The City of San Antonio's Animal Care Services conducted a study in 2019 to determine the total number of unrestrained dogs that were owned "roaming" and unowned "stray" animals. The results of their study predicted that $87.2-96.5 \%$ (CI 95\%) of all unrestrained dogs were likely owned "roaming" dogs [40]. This suggests that, in addition to the known privately-owned dogs, a high percentage of the present study's rescued and stray dogs were likely previously owned and lived in close contact with humans.

The present study showed that the highest apparent seroprevalence rate combined for the 6-year period was $11.7 \%$ for $D$. immitis. The heartworm antigen was also detected in almost half of the co-infected dogs. Such a high level of heartworm seroprevalence among the dog population in and around the city of San Antonio was not surprising. Furthermore, it is possible that the actual prevalence could be even higher as antigen blocking due to immune complex formation within the host may be a cause for false negative serologic test results [41, 42]. Historically, the counties of the studied area have had endemic foci, and the seroprevalence rates were shown to vary from 6.1 to $20.0 \%$ [29, 43]. For general comparison, the serological survey previously conducted in the continental US demonstrated that five southeastern states, namely Arkansas (6.8\%), Louisiana (6.0\%), Mississippi (7.4\%), South Carolina (5.7\%), and Texas (5.5\%) had the highest seroprevalence rates of $D$. immitis antigen-positive dogs [29]. To contrast the regional prevalence for the Southeast (2.9-3.9\%), the respective rates for the states of the Northeast, Midwest, and West ranged from 0.4 to $1.2 \%[29,42]$.

Similar to the heartworm rate, the apparent seroprevalence of E. canis and/or E. ewingii was high (8.4\%); however, this finding was quite unexpected. Previous studies demonstrated that, in Texas, the mean seroprevalence varied from 0.8 to $3.6 \%$ and the rates for the counties of the Greater San Antonio area did not exceed 2.0\% [29, $43,44]$. For comparison, the mean seroprevalence of the seropositive dogs across 48 states was $0.6 \%$ with the highest rates being observed in Arkansas (3.9\%), Oklahoma (3.8\%), Arizona (3.2\%), Mississippi (3.1\%), Tennessee (2.3\%), Kansas (2.2\%), North Carolina (2.1\%), Georgia (1.9\%), Missouri (1.9\%), and Virginia (1.8\%) [29]. Such an aberrantly high seroprevalence observed in this study could be potentially explained by two factors. Unlike the previous study where the test detected only antibodies to E. canis [29], the SNAP system used in the current work had the capacity to identify antibodies against an additional Ehrlichia species, E. ewingii [45]. Moreover, most of the dogs in this study $(85.2 \%)$ were from rescue groups or shelters. Thus, the fact that stray, rescued, or surrendered dogs were likely more frequently exposed to ticks (A. americanum and $R$. sanguineus) and devoid of any tick preventive products, could account for the high prevalence of anti-Ehrlichia antibodies in the studied dog population.

Compared to the heartworm and Ehrlichia seroprevalence rates, antibodies to A. phagocytophilum and/or A. 
platys were detected in much fewer dogs of the examined cohort (4.3\%). This seroprevalence rate was approximately several fold higher than the respective rates previously identified in Texas $(0.6 \%)$ and the other southeastern states (0.5-1.2\%) [29]. However, in 2019, Hodo et al. reported approximately $16 \%$ prevalence of Anaplasma spp. from a shelter in San Antonio proper [43]. The Anaplasma seroreactive dogs of this study were most likely exposed to $A$. platys rather than $A$. phagocytophilum, particularly as 8 dogs were Ehrlichia and Anaplasma seroreactive. Also, since $92 \%$ of the seropositive dogs were strays and maintained in shelters, $R$. sanguineus infestation (kennel tick) would be likely responsible for the transmission [45-49].

Contrary to the above results, the seroprevalence of $B$. burgdorferi identified in the current and previous studies is almost identical (0.2-0.3\%) and is well consistent with an overall low regional rate for the Southeast of the US $(1.0 \%)[27,29]$. Of note, Texas belongs to the low incidence state category with the mean annual rate of confirmed human Lyme borreliosis being 0.2 cases per 100, 000 population [50]. Interestingly, this incidence coincided with the seroprevalence rate of $B$. burgdorferi among dog populations examined in Texas by this and previous studies [27, 29]. It also should be mentioned that exposure to tick-borne relapsing fever Borrelia occurs in Texas; however, based upon a recent publication the B. burgdorferi C6 peptide-based SNAP test did not result in a false positive in experimentally infected dogs [51]. Also, in this study a travel history could not be established for the B. burgdorferi-positive dog. Lastly, the study showed that almost $4 \%$ of the dogs were coexposed or co-infected with 2-3 pathogens, indicating that the animals were exposed to different vectors during their lifetime $[8,9,52]$.

It is also important to note that this study had several limitations. First, the limited number of the examined animals could not fully reflect serological status of the entire dog population in the studied region. Additionally, the animals selected for sample collection likely represented a skewed cohort as there were no standardized inclusion criteria. Finally, serological testing alone could underestimate the actual disease prevalence. Previous heartworm studies reported that commercial serological kits may have low sensitivity when there are low parasite burdens, prepatent infections, infections by aging adult female worms with impaired fertility, infections with maleonly worms, or when the presence of microfilariae persists for 1-3 years after the death of adult females $[31,53]$. Thus, it is probable that the actual number of vector-borne disease cases in and around the Greater San Antonio area exceed those projected by this study.

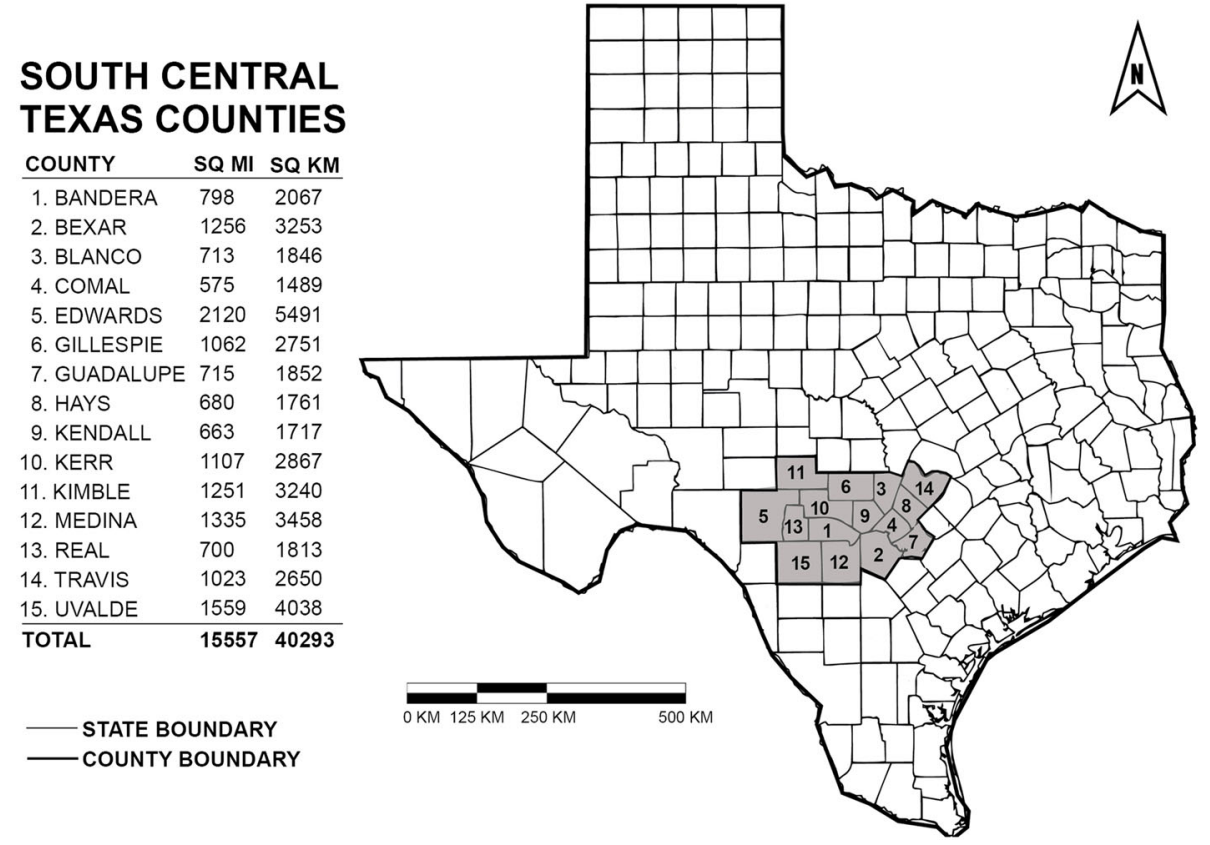

Fig. 1 The South Central region of Texas (the Greater San Antonio area). The map of the state of Texas (US) depicts all 15 counties from which the studied dogs were originated. The overall area of these counties is 15,557 mile $\left(40,292 \mathrm{~km}^{2}\right)$. The counties included: Bandera, Bexar, Blanco, Comal, Edwards, Gillespie, Guadalupe, Hays, Kendall, Kerr, Kimble, Medina, Real, Travis, and Uvalde. SQ MI and SQ KM denote square miles and square kilometers, respectively. The map was generated by using the 2019 Adobe Creative Cloud suite (Illustrator, Photoshop, and InDesign; www.adobe.com) 


\section{Conclusions}

Serology continues to be an important epidemiological modality to estimate the prevalence of zoonotic vectorborne diseases among dogs. The presented data may be useful to estimate the respective risks to human populations. Opportunistic testing of dogs presenting for elective surgical procedures may offer an effective way of assessing prevalence and/or risk factors for vector-borne diseases common to dogs and humans within a geographical region of interest.

\section{Methods}

Sera from dogs of different breeds were collected for serological testing as part of routine diagnostic service, and the data analysis was performed retrospectively, therefore no consent to participate in this study was required. Dogs' sera were screened using commercial ELISA-based test, SNAP 4Dx Plus, which detected antibodies to five bacterial pathogens, A. phagocytophilum, A. platys, B. burgdorferi, E. canis, E. ewingii, and an antigen of canine heartworm, D. immitis [45, 48, 49]. Sensitivity (95\% CI) and specificity $(95 \% \mathrm{CI})$ for the SNAP test as reported by the manufacturer were: $99.0 \%(94.3-99.9 \%)$ and $99.3 \%$ (97.4-99.9\%) for heartworm; 90.3\% (85.8-93.7\%) and 94.3\% (90.7-96.7\%) for Anaplasma; 97.1\% (94.0-98.8\%) and 95.3\% (92.7-97.2\%) for Ehrlichia; and 94.1\% (88.397.6\%) and 96.2\% (92.9-98.3\%) for B. burgdorferi [54]. Electronic medical records of dogs presented for elective ovariohysterectomy or castration at a high volume spay and neuter clinic in Boerne, Texas from June 2014 through December 2019 inclusive, were reviewed for the vector-borne disease serological test results. Included dogs belonged to a variety of private owners, rescue groups, and community animal control facilities. The studied dogs came from a 15-county region of the South Central Texas (the Greater San Antonio area) representing a geographical area of 15,557 mile $^{2}\left(40,292 \mathrm{~km}^{2}\right)$ (Fig. 1).

Statistical analysis was performed using Microsoft Excel 2016 and statistical software R 3.5.0 (R Core Team, 2018) [55]. For each examined variable, descriptive statistics were computed. Since the ages and body weights of dogs testing negative and positive for the assessed vector-borne diseases were not normally distributed, differences were determined using the nonparametric Mann-Whitney test. Pearson chi-square test was used to detect the sex difference between negative and positive groups. Statistical significance was set at $P<0.05$. Estimated true prevalence $(95 \% \mathrm{CI})$ calculations were performed using Epitools Epidemiological Calculators [56].

\section{Abbreviations}

CVBDs: Canine vector-borne diseases; Cl: Confidence interval; ELISA: Enzymelinked immunosorbent assay; SNAP: SNAP 4Dx Plus test; US: United States of America

\section{Acknowledgements}

The authors wish to thank Ms. Sandra Montalbo for assistance in preparing figure design and graphics. This work was supported by Hill Country Animal League and the Department of Veterinary Pathobiology, College of Veterinary Medicine and Biomedical Sciences, Texas A\&M University (US).

\section{Conflict of interest}

No conflicting financial interests exist.

\section{Authors' contributions}

JMF analyzed and interpreted data and drafted the initial manuscript. BB conducted the electronic medical record review, collated and analyzed data, and contributed to the written content of the manuscript. BP, the veterinarian responsible for medical care standards for Hill Country Animal League, contributed to the written content of the manuscript. SL performed statistical analysis. ASR conceived the experiment, analyzed and interpreted the data, and wrote the manuscript. The authors read and approved the final manuscript.

\section{Funding}

This work was supported by Hill Country Animal League and the Department of Veterinary Pathobiology, College of Veterinary Medicine and Biomedical Sciences, Texas A\&M University (US). The funders had no role in the design of the study and collection, analysis, and interpretation of data and in writing the manuscript.

\section{Availability of data and materials}

The datasets used and/or analysed during the current study are available from the corresponding author on reasonable request.

\section{Ethics approval and consent to participate}

Because all the sera were collected from dogs for serological testing as part of routine diagnostic service, and the data analysis was performed retrospectively, no consent to participate in this study or approval by institutional ethics committee were required (only retrospective records were reviewed). No administrative permissions were required to access the raw data used in this study.

\section{Consent for publication}

Not applicable.

\section{Competing interests}

The authors declare that they have no competing interests.

\section{Author details}

${ }^{1} H$ ill Country Animal League, 924 N. Main St, Boerne, TX 78006, USA. ${ }^{2}$ Statistical Collaboration Center, Department of Statistics, College of Science, Texas A\&M University, College Station, TX 77843, USA. ${ }^{3}$ Department of Veterinary Pathobiology, College of Veterinary Medicine and Biomedical Sciences, Texas A\&M University, College Station, TX 77843, USA.

Received: 6 August 2020 Accepted: 1 October 2020

Published online: 08 October 2020

\section{References}

1. Wilson AJ, Morgan ER, Booth M, Norman R, Perkins SE, Hauffe HC, et al. What is a vector? Philos Trans R Soc Lond B Biol Sci. 2017;372:1719.

2. Semenza JC, Menne B. Climate change and infectious diseases in Europe. Lancet Infect Dis. 2009;9(6):365-75.

3. Petersen $L R$, Beard CB, Visser SN. Combatting the increasing threat of vector-borne disease in the United States with a national vector-borne disease prevention and control system. Am J Trop Med Hyg. 2019;100(2): 242-5.

4. Rosenberg R, Lindsey NP, Fischer M, Gregory CJ, Hinckley AF, Mead PS, et al. Vital signs: trends in reported vectorborne disease cases - United States and territories, 2004-2016. MMWR Morb Mortal Wkly Rep. 2018;67(17):496-501.

5. Eder M, Cortes F, Teixeira de Siqueira Filha N, Araujo de Franca GV, Degroote $S$, Braga $C$, et al. Scoping review on vector-borne diseases in urban areas: transmission dynamics, vectorial capacity and co-infection. Infect Dis Poverty. 2018;7(1):90. 
6. Balakrishnan N, Musulin S, Varanat M, Bradley JM, Breitschwerdt EB. Serological and molecular prevalence of selected canine vector borne pathogens in blood donor candidates, clinically healthy volunteers, and stray dogs in North Carolina. Parasit Vectors. 2014;7:116.

7. Araya-Anchetta A, Busch JD, Scoles GA, Wagner DM. Thirty years of tick population genetics: a comprehensive review. Infect Genet Evol. 2015;29:164-79.

8. Otranto D, Dantas-Torres F, Breitschwerdt EB. Managing canine vectorborne diseases of zoonotic concern: part one. Trends Parasitol. 2009; 25(4):157-63

9. De Tommasi AS, Otranto D, Dantas-Torres F, Capelli G, Breitschwerdt EB, de Caprariis D. Are vector-borne pathogen co-infections complicating the clinical presentation in dogs? Parasit Vectors. 2013;6:97.

10. Maggi $R G$, Kramer $F$. A review on the occurrence of companion vectorborne diseases in pet animals in Latin America. Parasit Vectors. 2019; 12(1):145.

11. Ismail N, McBride JW. Tick-borne emerging infections: ehrlichiosis and anaplasmosis. Clin Lab Med. 2017;37(2):317-40

12. Nicholson WL, Allen KE, McQuiston JH, Breitschwerdt EB, Little SE. The increasing recognition of rickettsial pathogens in dogs and people. Trends Parasitol. 2010;26(4):205-12.

13. Rikihisa Y. New findings on members of the family Anaplasmataceae of veterinary importance. Ann N Y Acad Sci. 2006;1078:438-45.

14. Koenen F, Pascucci I, Jaenson TGT, Madder M, de Sousa R, Estrada-Pena A, et al. Tick-borne infections (including zoonoses) in Europe and the Mediterranean basin. In: Salman M, Tarres-Call J, editors. Ticks and tick-borne diseases geographical distribution and control stragegies in the euro-Asia region. Boston: Cabi; 2013. p. 33-75.

15. Boulanger N, Boyer P, Talagrand-Reboul E, Hansmann Y. Ticks and tickborne diseases. Med Mal Infect. 2019;49(2):87-97.

16. Sainz A, Roura X, Miro G, Estrada-Pena A, Kohn B, Harrus S, et al. Guideline for veterinary practitioners on canine ehrlichiosis and anaplasmosis in Europe. Parasit Vectors. 2015;8:75.

17. Arraga-Alvarado CM, Qurollo BA, Parra OC, Berrueta MA, Hegarty BC, Breitschwerdt EB. Case report: molecular evidence of Anaplasma platys infection in two women from Venezuela. Am J Trop Med Hyg. 2014; 91(6):1161-5.

18. Breitschwerdt EB, Hegarty BC, Qurollo BA, Saito TB, Maggi RG, Blanton LS, et al. Intravascular persistence of Anaplasma platys, Ehrlichia chaffeensis, and Ehrlichia ewingii DNA in the blood of a dog and two family members. Parasit Vectors. 2014;7:298.

19. Harvey JW, Simpson CF, Gaskin JM. Cyclic thrombocytopenia induced by a Rickettsia-like agent in dogs. J Infect Dis. 1978;137(2):182-8.

20. Maggi RG, Mascarelli PE, Havenga LN, Naidoo V, Breitschwerdt EB. Coinfection with Anaplasma platys, Bartonella henselae and Candidatus Mycoplasma haematoparvum in a veterinarian. Parasit Vectors. 2013;6:103.

21. Starkey LA, Barrett AW, Beall MJ, Chandrashekar R, Thatcher B, Tyrrell P, et al. Persistent Ehrlichia ewingii infection in dogs after natural tick infestation. J Vet Intern Med. 2015;29(2):552-5.

22. Stich RW, Schaefer JJ, Bremer WG, Needham GR, Jittapalapong S. Host surveys, ixodid tick biology and transmission scenarios as related to the tickborne pathogen, Ehrlichia canis. Vet Parasitol. 2008;158(4):256-73.

23. Breitschwerdt EB, Hegarty BC, Hancock SI. Sequential evaluation of dogs naturally infected with Ehrlichia canis, Ehrlichia chaffeensis, Ehrlichia equi, Ehrlichia ewingii, or Bartonella vinsonii. J Clin Microbiol. 1998;36(9):2645-51.

24. Kordick SK, Breitschwerdt EB, Hegarty BC, Southwick KL, Colitz CM, Hancock $\mathrm{SI}$, et al. Coinfection with multiple tick-borne pathogens in a Walker hound kennel in North Carolina. J Clin Microbiol. 1999;37(8):2631-8.

25. Rojas N, Castillo D, Marin P. Molecular detection of Ehrlichia chaffeensis in humans, Costa Rica. Emerg Infect Dis. 2015;21(3):532-4.

26. Scorpio DG, Dumler JS, Barat NC, Cook JA, Barat CE, Stillman BA, et al. Comparative strain analysis of Anaplasma phagocytophilum infection and clinical outcomes in a canine model of granulocytic anaplasmosis. Vector Borne Zoonotic Dis. 2011;11(3):223-9.

27. Littman MP, Gerber B, Goldstein RE, Labato MA, Lappin MR, Moore GE. ACVI M consensus update on Lyme borreliosis in dogs and cats. J Vet Intern Med. 2018:32(3):887-903.

28. Hoch H, Strickland K. Canine and feline dirofilariasis: life cycle, pathophysiology, and diagnosis. Compend Contin Educ Vet. 2008:30(3):133-40

29. Bowman D, Little SE, Lorentzen L, Shields J, Sullivan MP, Carlin EP. Prevalence and geographic distribution of Dirofilaria immitis, Borrelia burgdorferi, Ehrlichia canis, and Anaplasma phagocytophilum in dogs in the
United States: results of a national clinic-based serologic survey. Vet Parasitol. 2009;160(1-2):138-48.

30. Leidy J. A synopsis of entozoa and some of their ecto-congeners observed by the author. Proc Acad Nat Sci of Philadelphia. 1856;8:42-58.

31. Vieira AL, Vieira MJ, Oliveira JM, Simoes AR, Diez-Banos P, Gestal J. Prevalence of canine heartworm (Dirofilaria immitis) disease in dogs of Central Portugal. Parasite. 2014;21:5.

32. Montoya-Alonso JA, Mellado I, Carreton E, Cabrera-Pedrero ED, Morchon R, Simon F. Canine dirofilariosis caused by Dirofilaria immitis is a risk factor for the human population on the island of gran Canaria, Canary Islands, Spain. Parasitol Res. 2010;107(5):1265-9.

33. Montoya-Alonso JA, Carreton E, Juste MC, Mellado I, Morchon R, Simon F. Epidemiological survey of canine heartworm disease on the island of gran Canaria (Canary Islands - Spain) between 2000 and 2008. Vet Parasitol. 2010; 173:165-8.

34. Morchon R, Carreton E, Gonzalez-Miguel J, Mellado-Hernandez I. Heartworm disease (Dirofilaria immitis) and their vectors in Europe - new distribution trends. Front Physiol. 2012;3:196.

35. Lee AC, Montgomery SP, Theis JH, Blagburn BL, Eberhard ML. Public health issues concerning the widespread distribution of canine heartworm disease. Trends Parasitol. 2010:26(4):168-73.

36. Duncan AW, Correa MT, Levine JF, Breitschwerdt EB. The dog as a sentinel for human infection: prevalence of Borrelia burgdorferi C6 antibodies in dogs from southeastern and mid-Atlantic states. Vector Borne Zoonotic Dis. 2004;4(3):221-9.

37. Cleaveland S, Meslin FX, Breiman R. Dogs can play useful role as sentinel hosts for disease. Nature. 2006;440(7084):605.

38. Day MJ. One health: the importance of companion animal vector-borne diseases. Parasit Vectors. 2011:4:49.

39. Bowser NH, Anderson NE. Dogs (Canis familiaris) as sentinels for human infectious disease and application to Canadian populations: a systematic review. Vet Sci. 2018;5(4):83.

40. Unrestrained Dog Study (2019). https://www.sanantonio.gov. Accessed 23 Sept 2020.

41. DiGangi BA, Dworkin C, Stull JW, O'Quin J, Elser M, Marsh AE, et al. Impact of heat treatment on Dirofilaria immitis antigen detection in shelter dogs. Parasit Vectors. 2017;10:483.

42. Little SE, Beall MJ, Bowman DD, Chandrashekar R, Stamaris J. Canine infection with Dirofilaria immitis, Borrelia burgdorferi, Anaplasma spp., and Ehrlichia spp. in the United States, 2010-2012. Parasit Vectors. 2014;7:257.

43. Hodo CL, Rodriquez JY, Curtis-Robles R, Zecca IB, Snowden KF, Cummings $\mathrm{KJ}$, et al. Repeated cross-sectional study of Trypanosoma cruzi in shelter dogs in Texas, in the context of Dirofilaria immitis and tick-borne pathogen prevalence. J Vet Intern Med. 2019;33(1):158-66.

44. Beall MJ, Alleman AR, Breitschwerdt EB, Cohn LA, Couto CG, Dryden MW, et al. Seroprevalence of Ehrlichia canis, Ehrlichia chaffeensis and Ehrlichia ewingii in dogs in North America. Parasit Vectors. 2012;5:29.

45. Stillman BA, Monn M, Liu J, Thatcher B, Foster P, Andrews B, et al. Performance of a commercially available in-clinic ELISA for detection of antibodies against Anaplasma phagocytophilum, Anaplasma platys, Borrelia burgdorferi, Ehrlichia canis, and Ehrlichia ewingii and Dirofilaria immitis antigen in dogs. J Am Vet Med Assoc. 2014;245(1):80-6.

46. Gaunt S, Beall M, Stillman B, Lorentzen L, Diniz P, Chandrashekar R, et al. Experimental infection and co-infection of dogs with Anaplasma platys and Ehrlichia canis: hematologic, serologic and molecular findings. Parasit Vectors. 2010:3(1):33.

47. Simpson RM, Gaunt SD, Hair JA, Kocan KM, Henk WG, Casey HW. Evaluation of Rhipicephalus sanguineus as a potential biologic vector of Ehrlichia platys. Am J Vet Res. 1991;52(9):1537-41.

48. Liu J, Drexel J, Andrews B, Eberts M, Breitschwerdt E, Chandrashekar R. Comparative evaluation of 2 in-clinic assays for vector-borne disease testing in dogs. Top Companion Anim Med. 2018;33(4):114-8.

49. Chandrashekar R, Mainville CA, Beall MJ, O'Connor T, Eberts MD, Alleman $A R$, et al. Performance of a commercially available in-clinic ELISA for the detection of antibodies against Anaplasma phagocytophilum, Ehrlichia canis, and Borrelia burgdorferi and Dirofilaria immitis antigen in dogs. Am J Vet Res. 2010:71(12):1443-50

50. Schwartz AM, Hinckley AF, Mead PS, Hook SA, Kugeler KJ. Surveillance for Lyme disease - United States, 2008-2015. MMWR Surveill Summ. 2017:66(22):1-12.

51. Gettings JR, Lopez JE, Krishnavahjala A, Armstrong BA, Thompson AT, Yabsley MJ. Antibodies to Borrelia turicatae in experimentally infected dogs 
cross-react with Borrelia burgdorferi serologic assays. J Clin Microbiol. 2019; 57(9):e00628-19.

52. Colwell DD, Dantas-Torres F, Otranto D. Vector-borne parasitic zoonoses: emerging scenarios and new perspectives. Vet Parasitol. 2011;182(1):14-21.

53. McCall JW, Genchi C, Kramer L, Guerrero J, Dzimianski MT, Supakorndej P, et al. Heartworm and Wolbachia: therapeutic implications. Vet Parasitol. 2008;158(3):204-14.

54. SNAP 4Dx Plus Test: Test accuracy. (2016) https://www.idexx.com/files/ snap-4dx-plus-test-accuracy.pdf. Accessed 23 Sept 2020.

55. R Core Team. R: a language and environment for statistical computing. Vienna: R Foundation for Statistical Computing; 2013.

56. Sergeant ESG. Epitools epidemiological calculators; 2018. http://epitools. ausvet.com.au. Accessed 23 Sept 2020.

\section{Publisher's Note}

Springer Nature remains neutral with regard to jurisdictional claims in published maps and institutional affiliations.

Ready to submit your research? Choose BMC and benefit from:

- fast, convenient online submission

- thorough peer review by experienced researchers in your field

- rapid publication on acceptance

- support for research data, including large and complex data types

- gold Open Access which fosters wider collaboration and increased citations

- maximum visibility for your research: over $100 \mathrm{M}$ website views per year

At BMC, research is always in progress.

Learn more biomedcentral.com/submissions 